\title{
Can the microRNA signature distinguish between thyroid tumors of uncertain malignant potential and other well- differentiated tumors of the thyroid gland?
}

\author{
Sandra Lassalle 1,2,3,4 , Véronique Hofman ${ }^{1,2,3,4}$, Marius Ilie 1,2,3,4, \\ Christelle Bonnetaud ${ }^{3,4}$, Marie-Pierre Puisségur ${ }^{5}$, Patrick Brest ${ }^{1}$, \\ Céline Loubatier ${ }^{2}$, Nicolas Guevara ${ }^{6}$, Olivier Bordone ${ }^{3,4}$, Bruno Cardinaud ${ }^{5}$, \\ Kévin Lebrigand ${ }^{5}$, Géraldine Rios ${ }^{5}$, Joseph Santini ${ }^{6}$, Brigitte Franc ${ }^{7}$, \\ Bernard Mari ${ }^{5}$ Abir Al Ghuzlan ${ }^{8}$, Philippe Vielh ${ }^{8}$, Pascal Barbry ${ }^{5 *}$ and \\ Paul Hofman 1,2,3,4*
}

\footnotetext{
${ }^{1}$ INSERM ERI-21/EA4319, University of Nice Sophia Antipolis, 28 Avenue de Valombrose, 06107 Nice, France

${ }^{2} \mathrm{CHU}$ Nice, Laboratory of Clinical and Experimental Pathology, Pasteur Hospital, 06002 Nice, France

${ }^{3}$ Human Tissue Biobank Unit, Pasteur Hospital, 06002 Nice, France

${ }^{4}$ University of Nice Sophia Antipolis, Nice, France

${ }^{5}$ CNRS and University of Nice Sophia Antipolis, UMR 6097, Institut de Pharmacologie Moléculaire et Cellulaire, UMR 6097, 06560 Valbonne, France

${ }^{6}$ Department of Otorhinolaryngology, Pasteur Hospital, 06002 Nice, France

${ }^{7}$ Department of Pathology, Ambroise Paré Hospital, University of Versailles Saint-Quentin en Yvelines, Boulogne, France

${ }^{8}$ Department of Biopathology, Laboratoire de Recherche Translationnelle, Gustave Roussy Institut, Villejuif, Paris, France

(Correspondence should be addressed to P Hofman at INSERM ERI-21/EA4319, University of Nice Sophia Antipolis;

Email: hofman @ unice.fr; P Barbry at Institut de Pharmacologie Moléculaire et Cellulaire, CNRS 6097, 06560 Valbonne, France; Email: barbry@ipmc.cnrs.fr)

*(P Barbry and P Hofman contributed equally to this work)
}

\begin{abstract}
The term 'thyroid tumors of uncertain malignant potential' (TT-UMP) was coined by surgical pathologists to define well-differentiated tumors (WDT) showing inconclusive morphological evidence of malignancy or benignity. We have analyzed the expression of microRNA (miRNA) in a training set of 42 WDT of different histological subtypes: seven follicular tumors of UMP (FT-UMP), six WDT-UMP, seven follicular thyroid adenomas (FTA), 11 conventional papillary thyroid carcinomas (C-PTC), five follicular variants of PTC (FV-PTC), and six follicular thyroid carcinomas (FTC), which led to the identification of about 40 deregulated miRNAs. A subset of these altered miRNAs was independently validated by qRT-PCR, which included 18 supplementary TT-UMP (eight WDT-UMP and ten FT-UMP). Supervised clustering techniques were used to predict the first 42 samples. Based on the four possible outcomes (FTA, C-PTC, FV-PTC, and FTC), about $80 \%$ of FTA and C-PTC and $50 \%$ of FV-PTC and FTC samples were correctly assigned. Analysis of the independent set of 18 WDT-UMP by quantitative RT-PCR for the selection of the six most discriminating miRNAs was unable to separate FT-UMP from WDTUMP, suggesting that the miRNA signature is insufficient in characterizing these two clinical entities. We conclude that considering FT-UMP and WDT-UMP as distinct and specific clinical entities may improve the diagnosis of WDT of the thyroid gland. In this context, a small set of miRNAs (i.e. miR-7, miR-146a, miR-146b, miR-200b, miR-221, and miR-222) appears to be useful, though not sufficient per se, in distinguishing TT-UMP from other WDT of the thyroid gland.

Endocrine-Related Cancer (2011) 18 579-594
\end{abstract}




\section{Introduction}

The classification of well-differentiated tumors (WDT) of the thyroid gland according to histological criteria defines two distinct groups of neoplasia: benign (follicular thyroid adenoma, FTA) and malignant (papillary thyroid carcinoma, PTC; follicular thyroid carcinoma, FTC) neoplasia (De Lellis et al. 2004). However, there are borderline lesions that do not completely fulfill the different morphological criteria established to classify WDT of the thyroid gland, making the diagnosis and prognosis difficult. Besides, malignancy of some WDT of the thyroid gland can be difficult to diagnose based on the currently available diagnostic tools, which therefore lead to uncertain diagnosis and unpredictable prognosis (Suster 2006, Baloch \& LiVolsi 2007). In this regard, some authors have defined other categories of thyroid tumors such as 'thyroid tumors of uncertain malignancy potential' (TT-UMP; Williams 2000, Rosai 2005, Fonseca et al. 2006). This definition includes two histological subtypes named WDT-UMP and 'follicular tumor of UMP' (FT-UMP; Williams 2000, Rosai 2005, Fonseca et al. 2006). Despite recent progress in immunohistochemistry as well as in molecular biology in identifying relevant biomarkers for WDT (Papotti et al. 2005, Sobrinho-Simões et al. 2005, Fontaine et al. 2008), robust diagnostic tools predicting the degree of malignancy of borderline WDT such as FT-UMP or WDT-UMP are not available.

High-throughput approaches (genomics, transcriptomics, and/or proteomics) can be useful in identifying diagnostic and prognostic tools in cancer (Ludwig \& Weinstein 2005). Among these approaches, profiling of microRNAs (miRNAs), a class of small non-coding RNAs, has shown great promise for the diagnosis and prognosis of tumors (Calin \& Croce 2006 $a, b$ ). Altered expression of several miRNAs has already been reported in PTC (miR-21, miR-31, miR-146, miR-221, and $m i R-222)$, FTC (miR-197 and miR-346), and anaplastic thyroid carcinomas (miR-26a, miR-30a-5p, $m i R-30 d$, and $m i R-125 b$ ) (He et al. 2005a, Pallante et al. 2006, 2010, Weber et al. 2006, Tetzlaff et al. 2007, Visone et al. 2007, Chen et al. 2008). We therefore reasoned that some specific miRNA signatures might also be associated with 'borderline' WDT, i.e. TT-UMP, thus providing useful information for better diagnosis and prognosis of such lesions. We have thus conducted an extensive expression profiling study at the miRNA level on a training cohort of 42 WDT of the thyroid gland including 13 TT-UMP (seven FT-UMP and six WDT-UMP; Table 1). These 13 TT-UMP profiles were compared with those obtained from 16 PTC (11 conventional PTC (C-PTC) and five follicular variants of PTC (FV-PTC)), six FTC, and seven FTA in order to clarify the relationship existing between TT-UMP and the thyroid tumors already well characterized by morphological approaches (i.e. C-PTC, FV-PTC, FTC, and FTA). The obtained miRNA signature was then validated by qRT-PCR on an independent cohort including 18 additional tumors: eight WDT-UMP and ten FT-UMP.

\section{Materials and methods}

\section{Patients and thyroid specimens}

A total of 60 thyroid tumors consisting of 31 TT-UMP (17 FT-UMP and 14 WDT-UMP), 16 PTC (11 C-PTC and five FV-PTC), six FTC, and seven FTA, classified histologically according to the WHO classification (De Lellis et al. 2004), were included in this study. The samples were obtained at the Department of Pathology of Pasteur Hospital (Nice, France) and from the Gustave Roussy Institute (Villejuif, France). Of these 60 tumors, 13 TT-UMP, 16 PTC, six FTC, and seven FTA were assigned to the training/microarray set, whereas tumors in the training set and 18 supplementary TT-UMP (ten FT-UMP and eight WDT-UMP) were assigned to the validation/qRT-PCR set. Specimens of primary thyroid tumors and corresponding non-tumor thyroid tissues located at least $2 \mathrm{~cm}$ from the tumor were frozen in nitrogen and stored at $-80^{\circ} \mathrm{C}$. All patients provided a signed agreement for participating in the study, and the protocol was approved by the local ethics committee of the University of Nice. The epidemiological, clinical, and pathological features of patients included in this study are summarized in Tables 1 and 2 .

\section{Genetics of the samples}

Genomic DNA from tissue samples was extracted using the MagNA Pure Compact Nucleic Acid Isolation Large Volume kit (Roche) according to the manufacturer's instructions. Total RNA was extracted from samples with TRIzol solution (Invitrogen), and the integrity of the RNA was assessed using an Agilent Bioanalyser 2100 (Agilent, Palo Alto, CA, USA). Synthesis of cDNA was performed with $1 \mu \mathrm{g}$ total RNA at $37^{\circ} \mathrm{C}$ for $90 \mathrm{~min}$, using random hexamer primers and reverse transcriptase in accordance with the manufacturer's recommendations (Superscript III, Invitrogen). After initial denaturing at $95^{\circ} \mathrm{C}$ for $5 \mathrm{~min}$, gDNA (25 ng) (for $B R A F, K R A S$, and $N R A S$ analysis) or cDNA (for RET/PTC and PAX8/ $P P A R \gamma$ analysis) was subjected to 40 cycles of PCR, $94^{\circ} \mathrm{C}$ for $30 \mathrm{~s}, 58^{\circ} \mathrm{C}$ for $30 \mathrm{~s}, 72^{\circ} \mathrm{C}$ for $30 \mathrm{~s}$, for $B R A F$, $K R A S$, and $N R A S$, and $94^{\circ} \mathrm{C}$ for $30 \mathrm{~s}, 55^{\circ} \mathrm{C}$ for $2 \mathrm{~min}$, and 
Table 1 Epidemiological and pathological features of the training/microarray cohort

\begin{tabular}{|c|c|c|c|c|c|c|c|}
\hline Diagnosis & ID & $\begin{array}{c}\text { Tumor } \\
\text { size }(\mathrm{cm})\end{array}$ & Histopathology & pTNM & Gender & $\begin{array}{c}\text { Age } \\
\text { (years) }\end{array}$ & $\begin{array}{l}\text { History of } \\
\text { thyroid disease }\end{array}$ \\
\hline \multirow[t]{7}{*}{ FTA } & 2 & 3.5 & Microfollicular & - & Female & 46 & None \\
\hline & 10 & 2.8 & Microfollicular & - & Male & 31 & None \\
\hline & 11 & 2.0 & Microfollicular & - & Male & 68 & None \\
\hline & 20 & 1.4 & Heterofollicular & - & Male & 77 & None \\
\hline & 32 & 2.0 & Heterofollicular & - & Female & 51 & None \\
\hline & 37 & 4.0 & Microfollicular & - & Male & 42 & None \\
\hline & 40 & 4.0 & Heterofollicular & - & Male & 74 & None \\
\hline \multirow[t]{11}{*}{ C-PTC } & 15 & 3.5 & Papillary & pT3 N1M0 & Male & 23 & None \\
\hline & 23 & 1.5 & Papillary & pT1 NOMO & Female & 46 & $\begin{array}{l}\text { Hyperplastic } \\
\text { nodules }\end{array}$ \\
\hline & 26 & 1.0 & Papillary & pT1 NOM0 & Female & 80 & None \\
\hline & 31 & 1.5 & Papillary & pT3 NOMO & Female & 53 & $\begin{array}{l}\text { Hyperplastic } \\
\text { nodules }\end{array}$ \\
\hline & 39 & 2.8 & Papillary & pT2m N1M0 & Female & 41 & None \\
\hline & 12 & 1.3 & Papillary & pT3m N1M0 & Female & 43 & None \\
\hline & 24 & 2.3 & Papillary & pT3 N1M0 & Male & 34 & None \\
\hline & 28 & 1.5 & Papillary & pT1 N0M0 & Female & 69 & None \\
\hline & 33 & 1.1 & Papillary & pT1 N1M0 & Female & 18 & None \\
\hline & 34 & 1.8 & Papillary & pT1 N1M0 & Female & 39 & None \\
\hline & 35 & 1.2 & Papillary & pT1 N1M0 & Female & 43 & None \\
\hline \multirow[t]{5}{*}{ FV-PTC } & 4 & 3.0 & Heterofollicular, invasive & pT2 NOMO & Female & 28 & None \\
\hline & 6 & 3.0 & Heterofollicular, invasive & pT2 NOMO & Male & 36 & None \\
\hline & 13 & 1.4 & Heterofollicular, invasive & pT3 NOMO & Female & 50 & None \\
\hline & 17 & 2.5 & $\begin{array}{l}\text { Heterofollicular, } \\
\text { encapsulated }\end{array}$ & pT2 NOMO & Female & 39 & None \\
\hline & 29 & 1.3 & $\begin{array}{l}\text { Vesicular predominant, } \\
\text { invasive }\end{array}$ & pT3 NOMO & Female & 42 & None \\
\hline \multirow[t]{6}{*}{ WDT-UMP } & 3 & 3.0 & Heterofollicular & - & Female & 29 & $\begin{array}{l}\text { Hyperplastic } \\
\text { nodules }\end{array}$ \\
\hline & 9 & 2.8 & Heterofollicular & - & Female & 66 & None \\
\hline & 16 & 8.0 & Microfollicular & - & Female & 62 & Goiter \\
\hline & 18 & 2.5 & Microfollicular & - & Female & 34 & None \\
\hline & 22 & 2.5 & Microfollicular & - & Male & 66 & None \\
\hline & 30 & 6.0 & $\begin{array}{l}\text { Microfollicular and } \\
\text { trabecular }\end{array}$ & - & Female & 57 & None \\
\hline \multirow[t]{7}{*}{ FT-UMP } & 1 & 6.0 & Heterofollicular & - & Female & 78 & None \\
\hline & 5 & 2.5 & Microfollicular & - & Female & 66 & $\begin{array}{l}\text { Hyperplastic } \\
\text { nodules }\end{array}$ \\
\hline & 7 & 3.0 & Heterofollicular & - & Male & 45 & None \\
\hline & 14 & 6.5 & Microfollicular & - & Male & 60 & None \\
\hline & 25 & 3.0 & Microfollicular & - & Male & 53 & None \\
\hline & 27 & 2.5 & Heterofollicular & - & Female & 36 & None \\
\hline & 36 & 3.5 & Microfollicular & - & Female & 55 & None \\
\hline \multirow[t]{6}{*}{ FTC } & 8 & 3.2 & $\begin{array}{l}\text { Well-differentiated } \\
\text { minimally invasive }\end{array}$ & pT2NOMO & Female & 54 & None \\
\hline & 19 & 3.5 & $\begin{array}{l}\text { Well-differentiated } \\
\text { minimally invasive }\end{array}$ & pT2NOMO & Male & 61 & None \\
\hline & 21 & 2.2 & $\begin{array}{l}\text { Oncocytic, minimally } \\
\text { invasive }\end{array}$ & pT2NOMO & Female & 30 & None \\
\hline & 38 & 2.7 & $\begin{array}{l}\text { Well-differentiated } \\
\text { minimally invasive }\end{array}$ & pT2NOMO & Female & 78 & None \\
\hline & 41 & 1.3 & $\begin{array}{l}\text { Oncocytic, minimally } \\
\text { invasive }\end{array}$ & pT3NOMO & Female & 27 & None \\
\hline & 42 & 2.0 & $\begin{array}{l}\text { Well-differentiated } \\
\text { minimally invasive }\end{array}$ & pT1N0M0 & Female & 28 & None \\
\hline
\end{tabular}

FTA, follicular thyroid adenoma; C-PTC, classical papillary thyroid carcinoma; FV-PTC, follicular variant of papillary carcinoma; WDT-UMP, well-differentiated tumor of uncertain malignant potential; FT-UMP, follicular tumor of uncertain malignant potential; FTC, follicular thyroid carcinoma. Column 2 'ID' gives the reference number of each patient. pTNM according to the UICC (6 ${ }^{\text {th }}$ edition). 
Table 2 Epidemiological and pathological features of the validation/qRT-PCR cohort

\begin{tabular}{|c|c|c|c|c|c|c|}
\hline Diagnosis & ID & $\begin{array}{l}\text { Tumor } \\
\text { size }(\mathrm{cm})\end{array}$ & Histopathology & Gender & $\begin{array}{c}\text { Age } \\
\text { (years) }\end{array}$ & $\begin{array}{l}\text { History of } \\
\text { thyroid disease }\end{array}$ \\
\hline \multirow[t]{8}{*}{ WDT-UMP } & 43 & 3.0 & Heterofollicular & Female & 26 & None \\
\hline & 44 & 4 & Heterofollicular & Female & 31 & None \\
\hline & 45 & 2.4 & Heterofollicular & Female & 44 & None \\
\hline & 46 & 1.5 & Microfollicular & Male & 40 & None \\
\hline & 48 & 3 & Microfollicular & Male & 26 & None \\
\hline & 49 & 3.5 & Heterofollicular & Female & 20 & None \\
\hline & 50 & 5 & Microfollicular & Female & 77 & None \\
\hline & 51 & 1.5 & Microfollicular & Female & 59 & None \\
\hline \multirow[t]{10}{*}{ FT-UMP } & 53 & 2 & $\begin{array}{l}\text { Oncocytic microfollicular } \\
\text { and trabecular }\end{array}$ & Male & 74 & None \\
\hline & 54 & 1.8 & Microfollicular & Male & 46 & None \\
\hline & 55 & 3 & $\begin{array}{l}\text { Oncocytic microfollicular } \\
\text { and trabecular }\end{array}$ & Female & 43 & None \\
\hline & 56 & 3.0 & $\begin{array}{l}\text { Oncocytic microfollicular } \\
\text { and trabecular }\end{array}$ & Female & 60 & None \\
\hline & 57 & 0.8 & Heterofollicular & Female & 35 & None \\
\hline & 58 & 1.2 & Heterofollicular & Female & 16 & None \\
\hline & 380326 & 2 & Heterofollicular & Female & 51 & NS \\
\hline & 07H01751 & 2.5 & Heterofollicular & Female & 51 & NS \\
\hline & $08 \mathrm{H} 01741$ & 1.3 & Microfollicular and trabecular & Female & 25 & NS \\
\hline & $08 \mathrm{H} 05210$ & 3.3 & Heterofollicular & Female & 51 & NS \\
\hline
\end{tabular}

WDT-UMP, well-differentiated tumor of uncertain malignant potential; FT-UMP, follicular tumor of uncertain malignant potential; NS, not specified. Column 2 'ID' gives the reference number of each patient.

$72^{\circ} \mathrm{C}$ for $2 \mathrm{~min}$, for $R E T / \mathrm{PTC} 1$ and 3 using Taq platinum (Invitrogen), followed by final extension at $72^{\circ} \mathrm{C}$ for 7 min. DNA fragments from all patients were bidirectionally sequenced on an $\mathrm{ABI} 310$ sequencer using the Big Dye Terminator kit (Applied Biosystems, Inc., Foster City, CA, USA).

\section{miRNA isolation, microarray hybridization, and analysis}

Following total RNA extraction, the miRvana miRNA isolation kit was used for the isolation and enrichment of small RNA fractions (Ambion, Austin, TX, USA), according to the manufacturer's protocol. Each small RNA fraction (700 ng) was chemically labeled with Alexa Fluors as described previously (Babak et al. 2004). The RNA from each tumor was hybridized with the RNA from the corresponding non-tumor thyroid tissue. Experiments were performed with a miRNA microarray, referenced in GEO under the accession number GPL4717 (http://www.ncbi.nlm.nih.gov/geo/ query/acc.cgi $?$ acc $=$ GPL4717). The array contained 1902 different sequences against 1449 distinct miRNAs (Sanger miRNA database, release 8.2, ftp:// mirbase.org/pub/mirbase/8.2/) and 35 control RNAs. The microarray was derived from the one described elsewhere (Triboulet et al. 2007). It also included 167 sequences (Legendre et al. 2006). The specificity of the probes was defined by Le Brigand et al. (2006). All hybridization data have been deposited in GEO under the reference GSE15740 via the Mediante information system (Le Brigand \& Barbry 2007). Normalization was obtained using the software limma from Bioconductor (www.bioconductor.org; Smyth 2005), according to the variance stabilization and calibration for microarray data (VSN) approach described by Huber et al. (2002).

Each pathological sample was compared with its matched control. This control was taken from the same patient at a large distance from the tumor. Results are therefore shown as $\log _{2}\left(\operatorname{signal}_{\text {tumor }} /\right.$ signal $\left._{\text {control }}\right)$. The Bayesian approach developed by Smyth and colleagues was then used to identify probes modified in at least one of the different clinical conditions (Smyth 2005). To that end, intensities were background corrected and normalized according to Huber et al. (2002). A linear model of the data was calculated, and the 21 pairs of contrast between FTA, WDT-UMP, FT-UMP, FV-PTC, FTC, and C-PTC (mutated or not for $B R A F$ ) were evaluated. We used cutoff values equal to 7.5 for the $\log _{2}$ (signal), 0.7 for the $\log _{2}$ (ratio), and 0.01 for the adjusted $P$ value.

\section{Quantitative RT-PCR analysis}

Values for miRNA expression, measured using microarrays, were confirmed by quantitative real-time RT-PCR for the selection of ten miRNAs (miR-31, 
$m i R-34 a, m i R-100, m i R-146, m i R-152, m i R-199 a$, $m i R-199 b, m i R-221, m i R-222$, and $m i R-451)$ according to the manufacturer's protocol (Applied Biosystems, Carlsbad, CA, USA). Ten miRNAs compiled from our study and from other studies (He et al. 2005a, Pallante et al. 2006, Chen et al. 2008, Nikiforova et al. 2008, Sheu et al. 2010) were also quantified independently, in the validation set $(m i R-7, m i R-21, m i R-31, m i R-100$, miR-146b, miR-181b, miR-199a, miR-200b, miR-221, and $m i R-222)$. Briefly, total RNA was reverse transcribed to cDNA with a miRNA-specific primer (TaqMan MicroRNA reverse transcription kit, Applied Biosystems). RT-PCR was performed using a 7500 Fast Real-Time PCR (Applied Biosystems), with TaqMan probes, as follows: $95^{\circ} \mathrm{C}$ for $10 \mathrm{~min}$ and $95^{\circ} \mathrm{C}$ for $15 \mathrm{~s}$ and $60^{\circ} \mathrm{C}$ for $1 \mathrm{~min}$ (for 40 cycles). Statistical significance was defined as a $P$ value $<0.05$.

\section{In situ hybridization}

In situ hybridization (ISH) to detect $m i R-7, m i R-200 b$, $m i R-221$, and $m i R-222$ was performed using frozen tissues including four normal thyroids, four C-PTC, four WDT-UMP, four FT-UMP, and two FTC. Probes for ISH were purchased from Exiqon (Copenhagen, Denmark) and consisted of locked nucleic acid (LNA) oligonucleotide probes labeled at both the 500 and 30 ends with digoxigenin. Microwave pre-treatment was performed in a $700 \mathrm{~W}$ oven in $10 \mathrm{mM}$ citric acid, $\mathrm{pH} 6.0$, for $12 \mathrm{~min}$ followed by cooling at room temperature for $20 \mathrm{~min}$. Tissues were then digested in $25 \mathrm{mg} / \mathrm{ml}$ proteinase $\mathrm{K}$ solution at $37^{\circ} \mathrm{C}$ for $10 \mathrm{~min}$. Hybridization was performed at $55^{\circ} \mathrm{C}$ overnight in a humidified chamber using $200 \mathrm{nM}$ probe. Slides were washed in $2 \mathrm{M}$ sodium chloride-sodium citrate (SSC) at $50^{\circ} \mathrm{C}$ for $20 \mathrm{~min}$, followed by washing in $0.5 \mathrm{M} \mathrm{SSC}$ at $50^{\circ} \mathrm{C}$ for $20 \mathrm{~min}$. The slides were then rinsed in Trisbuffered saline (TBS, pH 7.5; buffer A) and incubated with an anti-digoxigenin-alkaline phosphataselabeled antibody (Roche) at 1:200 dilution in buffer A with $1 \%$ normal swine serum and $0.3 \%$ Triton $\mathrm{X}-100$ for $3 \mathrm{~h}$. After washing in buffer A and then in buffer C (TBS, pH 9.5), the slides were incubated with nitrobluetetrazolium chloride and 5-bromo-4chloro-3-indolyl phosphate, at $\mathrm{pH} 9.5$ in buffer $\mathrm{C}$ and developed between $30 \mathrm{~min}$ to $3 \mathrm{~h}$. The negative control consisted of substituting a scrambled probe (Exiqon) at the same concentration as the hybridization probe. As a second control, the slides were treated with RNAse A $(250 \mu \mathrm{g} / \mathrm{ml}$ from Sigma $)$ before hybridization.

\section{Statistical analysis}

The Student's $t$-test was used to analyze the significant differences in the real-time RT-PCR experiments. A $P$ value $<0.05$ with the two-tailed test was considered significant.

\section{Results}

\section{The genetic mutations and rearrangements in thyroid tumor samples}

A BRAF mutation was identified in six of the 11 C-PTC. No BRAF mutation was found in the group of TT-UMP (Table 3). Two WDT-UMP and one FT-UMP had NRAS mutations and one FT-UMP had a $P A X 8 / P P A R \gamma$ rearrangement. No RET/PTC rearrangement was found in TT-UMP.

\section{The miRNA expression profile of well-differentiated thyroid tumors}

Figure 1 shows hierarchical clustering of 42 pairs of miRNA samples (tumor versus control; training set) for the selection of 83 miRNAs. The distance was measured using the Spearman's distance on the matrix of $\log _{2}$ (ratio). The classification was performed using a complete agglomeration method. Two main arms were detected. The first arm contained all C-PTC samples (mutated or not in $B R A F$ ), four of the five FV-PTC samples, one WDT-UMP, one of the seven FTA, and one of the six FTC. The second arm is more heterogenous and contained most of the FTA (six of the seven), all FT-UMP (seven samples), and also five WDT-UMP and five FTC. Overall, Fig. 1 shows a clear consistency between miRNA profiling and papillary carcinoma diagnosis, corresponding either to C-PTC or to FV-PTC. FT-UMP showed some proximity with adenomas. The FTC and WDT-UMP samples did not appear in the same group as the others. Figure 1 also highlights some extreme $\log _{2}$ (ratio)s observed for miRNAs, such as miR-146a, miR-146b, $m i R-21$, $m i R-221$, and $m i R-222$. The results are summarized in Table 4, which represent the average $\log _{2}$ (ratios) for the 43 most discriminative miRNAs. The relationship between the different clinical groups was also visualized using paired comparison of the $\log _{2}$ (ratio) (Fig. 2). A linear relationship between the average of two clinical conditions indicates proximity between them. This was the case when mutBRAF-C-PTC and wtBRAF C-PTC were compared, for which a coefficient of correlation close to 1 (i.e. 0.94) was observed. This representation illustrates the relationships existing between mutBRAF C-PTC, 
Table 3 Mutations and rearrangements detected in the different tumor specimens of the training set used for miRNA analysis

\begin{tabular}{|c|c|c|c|c|c|c|c|}
\hline Diagnosis & References & B-RAF & K-RAS & N-RAS & H-RAS & RET/PTC1-3 & PAX8/PPAR $\gamma$ \\
\hline \multirow[t]{7}{*}{ FTA } & 2 & NS & NS & NS & NS & NS & Negative \\
\hline & 10 & NS & NS & NS & NS & NS & Negative \\
\hline & 11 & NS & NS & NS & NS & NS & Negative \\
\hline & 20 & NS & NS & NS & NS & NS & Negative \\
\hline & 32 & NS & NS & NS & NS & NS & Negative \\
\hline & 37 & NS & NS & NS & NS & NS & Negative \\
\hline & 40 & NS & NS & NS & NS & NS & Negative \\
\hline \multirow[t]{11}{*}{ C-PTC } & 15 & Negative & Negative & Negative & Negative & Negative & Negative \\
\hline & 23 & Negative & Negative & Negative & Negative & Negative & Negative \\
\hline & 26 & Negative & Negative & Negative & Negative & Negative & Negative \\
\hline & 31 & Negative & Negative & Negative & Negative & Negative & Negative \\
\hline & 39 & Negative & Negative & Negative & Negative & Negative & Negative \\
\hline & 12 & Positive & Negative & Negative & Negative & Negative & Negative \\
\hline & 24 & Positive & Negative & Negative & Negative & Negative & Negative \\
\hline & 28 & Positive & Negative & Negative & Negative & Negative & Negative \\
\hline & 33 & Positive & Negative & Negative & Negative & Negative & Negative \\
\hline & 34 & Positive & Negative & Negative & Negative & Negative & Negative \\
\hline & 35 & Positive & Negative & Negative & Negative & Negative & Negative \\
\hline \multirow[t]{5}{*}{ FV-PTC } & 4 & Negative & Negative & Negative & Negative & Positive & Negative \\
\hline & 6 & Negative & Negative & Negative & Negative & Negative & Negative \\
\hline & 13 & Negative & Negative & Negative & Negative & Negative & Negative \\
\hline & 17 & Negative & Negative & Negative & Negative & Negative & Negative \\
\hline & 29 & Negative & Negative & Negative & Negative & Negative & Negative \\
\hline \multirow[t]{6}{*}{ WDT-UMP } & 3 & Negative & Negative & Negative & Negative & Negative & Negative \\
\hline & 9 & Negative & Negative & Negative & Negative & Negative & Negative \\
\hline & 16 & Negative & Negative & Positive & Negative & Negative & Negative \\
\hline & 18 & Negative & Negative & Negative & Negative & Negative & Negative \\
\hline & 22 & Negative & Negative & Positive & Negative & Negative & Negative \\
\hline & 30 & Negative & Negative & Negative & Negative & Negative & Negative \\
\hline \multirow[t]{7}{*}{ FT-UMP } & 1 & Negative & Negative & Negative & Negative & Negative & Negative \\
\hline & 5 & Negative & Negative & Negative & Negative & Negative & Negative \\
\hline & 7 & Negative & Negative & Negative & Negative & Negative & Positive \\
\hline & 14 & Negative & Negative & Negative & Negative & Negative & Negative \\
\hline & 25 & Negative & Negative & Negative & Negative & Negative & Negative \\
\hline & 27 & Negative & Negative & Positive & Negative & Negative & Negative \\
\hline & 36 & Negative & Negative & Negative & Negative & Negative & Negative \\
\hline \multirow[t]{6}{*}{ FTC } & 8 & NS & Negative & Negative & Negative & Negative & Negative \\
\hline & 19 & NS & Negative & Negative & Negative & Negative & Negative \\
\hline & 21 & NS & Negative & Negative & Negative & Negative & Positive \\
\hline & 38 & NS & Negative & Negative & Negative & Negative & Negative \\
\hline & 41 & NS & Negative & Negative & Negative & Negative & Positive \\
\hline & 42 & NS & Negative & Negative & Negative & Negative & Negative \\
\hline
\end{tabular}

FTA, follicular thyroid adenoma; C-PTC, classical papillary thyroid carcinoma; FV-PTC, follicular variant papillary carcinoma; WDT-UMP, well-differentiated tumor of uncertain malignant potential; FT-UMP, follicular tumor of uncertain malignant potential; FTC, follicular thyroid carcinoma; NS, not searched. Column 2 of the table gives the reference of each patient.

wtBRAF C-PTC, and FV-PTC on the one hand and FTA, FTC, FT-UMP, and WDT-UMP on the other hand.

\section{Validation of differentially expressed miRNAs by real-time qRT-PCR}

Both the training set of thyroid tumors analyzed using microarrays and an independent set of TT-UMP were analyzed using qRT-PCR (Fig. 3).
The values for the average fold difference obtained by qRT-PCR TaqMan for each miRNA were plotted against the values for the fold change obtained from microarray data. A good correlation was obtained between the results of microarray and qRT-PCR (Fig. 3). In the samples obtained from the validation cohort, seven of the ten miRNAs quantified by qPCR showed significant modulation (Table 5). In particular, $m i R-221$ and $m i R$-222 were upregulated 


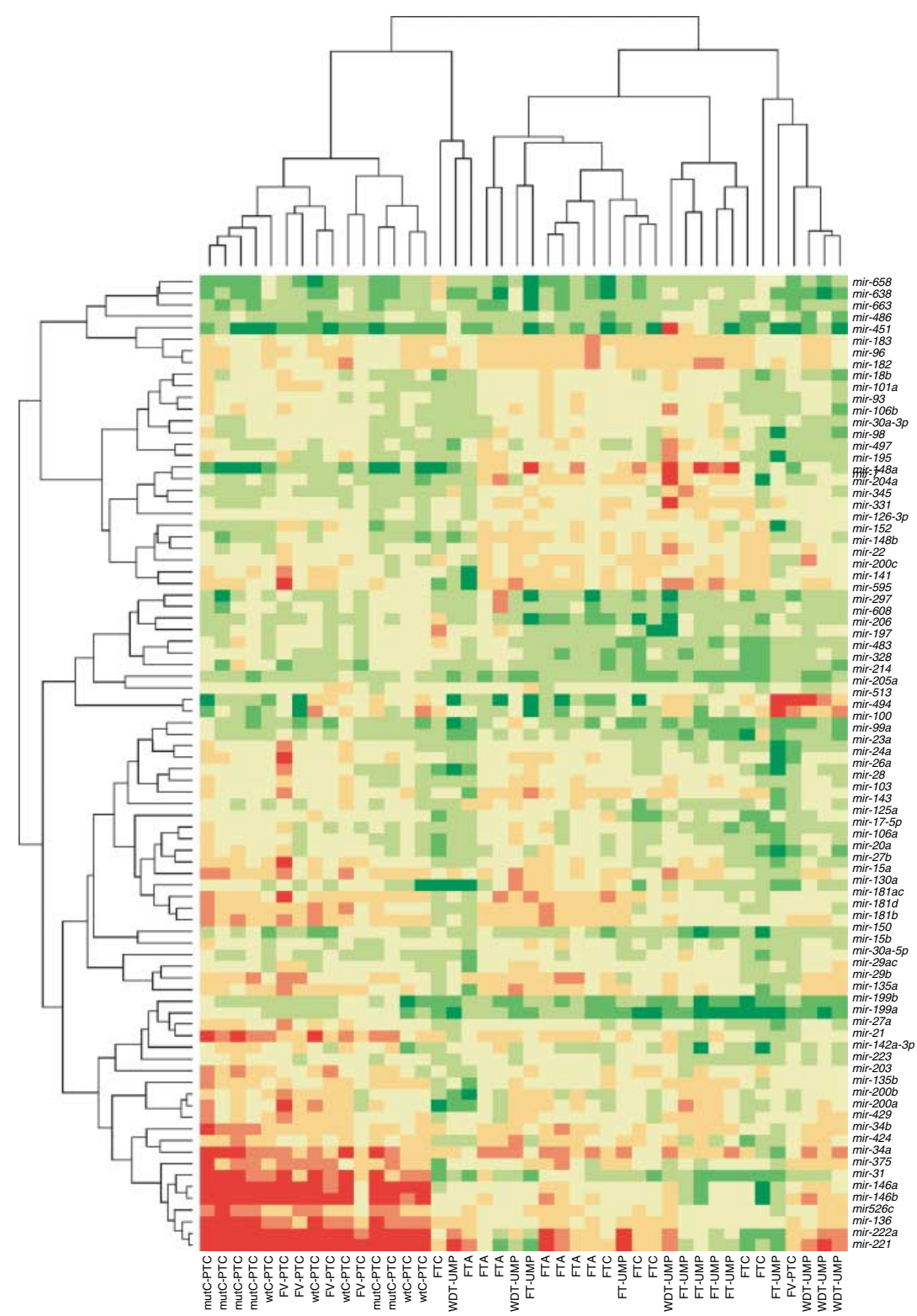

Figure 1 Heat map of 84 differentially expressed miRNAs analyzed for 42 patients. The cutoff values equal to 7.5 for the log 2 (signal), \pm 0.7 for the $\log _{2}$ (ratio), and 0.01 for the adjusted $P$ value were used. Each column corresponds to one patient: five C-PTC with wildtype $B R A F$, six C-PTC with mutated BRAF, five FV-PTC, seven adenomas, six FTC, six WDT-UMP, and seven FT-UMP were analyzed. Each line corresponds to one of the 84 miRNAs found differentially expressed between normal and pathological tissues, or differing between at least two experimental groups. The false color image represents the $\log _{2}($ ratio) between lesion and control biopsies. The $\log _{2}$ (ratio) was measured between normal and pathological RNA extracted from the same patient. Control tissue was taken at a large distance from the lesion in order to minimize the risk of contamination with tumor tissue. Distances were measured according to Spearman. Clustering was performed using a complete method. wtC-PTC, wild-type classical papillary thyroid carcinoma (C-PTC non-mutated for BRAF V600); mutC-PTC, mutated classical papillary papillary thyroid carcinoma (C-PTC mutated for BRAF V600). FV-PTC, follicular variant of papillary thyroid carcinoma; FTC, follicular thyroid carcinoma; FTA, follicular thyroid adenoma; WDT-UMP, well-differentiated tumors of uncertain malignant potential; FT-UMP, follicular tumor of uncertain malignant potential.

in WDT-UMP and FT-UMP. $m i R-146 b$ and $m i R-34 a$ were upregulated and $m i R-199 a$ was downregulated in WDT-UMP. However, we were not able to identify in the supervision group any miRNA(s) showing differential expression between WDT-UMP and FT-UMP. This result clearly indicates that miRNAs cannot be used to distinguish between these two subgroups. 
S Lassalle, $P$ Barbry, $P$ Hofman et al.: MicroRNAs and thyroid tumors

Table 4 A summary of the differentially expressed miRNAs between tumor and unaffected thyroid tissue (training set). Mean of log 2 (fold changes) are represented

\begin{tabular}{|c|c|c|c|c|c|c|c|}
\hline miRNA & FTA & FTC & FT-UMP & WDT-UMP & FV-PTC & wtC-PTC & mutC-PTC \\
\hline mir-513 & $-1.86 \pm 0.67$ & $-0.54 \pm 0.5$ & $-0.03 \pm 0.93$ & $0.37 \pm 0.86$ & $0.2 \pm 1.2$ & $0.17 \pm 0.47$ & $-0.78 \pm 0.62$ \\
\hline mir-494 & $-0.74 \pm 0.21$ & $-0.1 \pm 0.36$ & $-0.25 \pm 0.73$ & $0.74 \pm 0.3$ & $0.03 \pm 0.83$ & $0.61 \pm 0.54$ & $-0.7 \pm 0.43$ \\
\hline mir-29ac & $-0.23 \pm 0.24$ & $-0.47 \pm 0.2$ & $0.03 \pm 0.15$ & $0.26 \pm 0.13$ & $0 \pm 0.23$ & $-0.45 \pm 0.15$ & $0.22 \pm 0.05$ \\
\hline mir-15b & $0.1 \pm 0.19$ & $-0.6 \pm 0.17$ & $-0.53 \pm 0.2$ & $-0.08 \pm 0.19$ & $-0.58 \pm 0.23$ & $-0.22 \pm 0.15$ & $-0.03 \pm 0.17$ \\
\hline mir-125a & $0.03 \pm 0.1$ & $-0.91 \pm 0.33$ & $-0.24 \pm 0.1$ & $-0.46 \pm 0.11$ & $-0.48 \pm 0.15$ & $-0.07 \pm 0.07$ & $0.03 \pm 0.09$ \\
\hline mir-27a & $-0.04 \pm 0.13$ & $-0.84 \pm 0.1$ & $-0.54 \pm 0.39$ & $-0.24 \pm 0.25$ & $0.19 \pm 0.67$ & $0.23 \pm 0.28$ & $0.55 \pm 0.14$ \\
\hline mir-26a & $-0.23 \pm 0.3$ & $-1.03 \pm 0.3$ & $-0.55 \pm 0.47$ & $-0.58 \pm 0.45$ & $-0.08 \pm 0.42$ & $-0.14 \pm 0.18$ & $-0.28 \pm 0.13$ \\
\hline mir-130a & $-0.24 \pm 0.37$ & $-0.93 \pm 0.51$ & $-0.62 \pm 0.32$ & $-0.24 \pm 0.6$ & $-0.58 \pm 0.35$ & $-0.91 \pm 0.4$ & $-0.23 \pm 0.15$ \\
\hline mir-143 & $0.3 \pm 0.08$ & $-0.82 \pm 0.31$ & $-0.8 \pm 0.21$ & $-0.19 \pm 0.21$ & $-0.26 \pm 0.21$ & $-0.11 \pm 0.25$ & $-0.48 \pm 0.15$ \\
\hline mir-497 & $0.42 \pm 0.2$ & $-0.4 \pm 0.14$ & $0.06 \pm 0.23$ & $-0.53 \pm 0.5$ & $-0.02 \pm 0.15$ & $-0.49 \pm 0.28$ & $-0.57 \pm 0.16$ \\
\hline mir-98 & $0.17 \pm 0.23$ & $-0.38 \pm 0.08$ & $-0.36 \pm 0.46$ & $-0.63 \pm 0.39$ & $-0.19 \pm 0.26$ & $0.01 \pm 0.15$ & $-0.45 \pm 0.3$ \\
\hline mir-200b & $-0.46 \pm 0.36$ & $-0.34 \pm 0.31$ & $0.47 \pm 0.26$ & $-0.14 \pm 0.41$ & $0.11 \pm 0.47$ & $0.52 \pm 0.13$ & $0.41 \pm 0.09$ \\
\hline mir-429 & $-0.11 \pm 0.15$ & $-0.5 \pm 0.22$ & $0.58 \pm 0.15$ & $0.39 \pm 0.16$ & $0.63 \pm 0.31$ & $0.7 \pm 0.2$ & $0.47 \pm 0.21$ \\
\hline mir-181d & $0.6 \pm 0.25$ & $-0.26 \pm 0.25$ & $0.17 \pm 0.23$ & $0 \pm 0.23$ & $0.47 \pm 0.26$ & $0.75 \pm 0.27$ & $0.99 \pm 0.24$ \\
\hline mir-99a & $-0.59 \pm 0.29$ & $-0.8 \pm 0.46$ & $-1.36 \pm 0.25$ & $-0.71 \pm 0.31$ & $-0.33 \pm 0.15$ & $-0.46 \pm 0.26$ & $-0.62 \pm 0.16$ \\
\hline mir-100 & $-0.99 \pm 0.27$ & $-1.33 \pm 0.25$ & $-1.5 \pm 0.24$ & $-1.16 \pm 0.45$ & $-1.33 \pm 0.3$ & $-0.8 \pm 0.32$ & $-0.81 \pm 0.13$ \\
\hline mir-199b & $-1.63 \pm 0.17$ & $-2.03 \pm 0.18$ & $-1.78 \pm 0.4$ & $-2.07 \pm 0.14$ & $-0.86 \pm 0.23$ & $-1.26 \pm 0.55$ & $-1.05 \pm 0.22$ \\
\hline mir-199a & $-0.86 \pm 0.12$ & $-2.16 \pm 0.21$ & $-2.35 \pm 0.2$ & $-1.98 \pm 0.17$ & $-0.85 \pm 0.26$ & $-0.67 \pm 0.3$ & $-0.27 \pm 0.05$ \\
\hline mir-15a & $0.41 \pm 0.18$ & $0.01 \pm 0.32$ & $0.38 \pm 0.26$ & $1 \pm 0.33$ & $0.44 \pm 0.53$ & $1.16 \pm 0.18$ & $1.01 \pm 0.16$ \\
\hline mir-181b & $0.58 \pm 0.33$ & $-0.07 \pm 0.17$ & $0.31 \pm 0.21$ & $0.74 \pm 0.19$ & $1.03 \pm 0.33$ & $0.79 \pm 0.2$ & $1.14 \pm 0.19$ \\
\hline mir-222a & $0.89 \pm 0.47$ & $-0.34 \pm 0.54$ & $-0.3 \pm 0.5$ & $1.45 \pm 0.23$ & $2.41 \pm 0.55$ & $3.27 \pm 0.18$ & $3.81 \pm 0.22$ \\
\hline mir-221 & $1.19 \pm 0.64$ & $0.2 \pm 0.56$ & $-0.43 \pm 0.51$ & $1.56 \pm 0.47$ & $2.47 \pm 0.54$ & $3.36 \pm 0.11$ & $3.87 \pm 0.11$ \\
\hline mir-34a & $1.36 \pm 0.27$ & $0.25 \pm 0.34$ & $0.78 \pm 0.47$ & $1.63 \pm 0.21$ & $1 \pm 0.26$ & $1.56 \pm 0.24$ & $2.2 \pm 0.24$ \\
\hline mir-146b & $1.15 \pm 0.58$ & $-0.3 \pm 0.3$ & $-0.22 \pm 0.53$ & $1.75 \pm 0.87$ & $2.87 \pm 1.21$ & $4.17 \pm 0.48$ & $4.82 \pm 0.15$ \\
\hline mir-345 & $0.24 \pm 0.24$ & $0.06 \pm 0.33$ & $0.93 \pm 0.16$ & $0.78 \pm 0.5$ & $-0.06 \pm 0.14$ & $-0.65 \pm 0.22$ & $-0.79 \pm 0.15$ \\
\hline mir-7 & $0.56 \pm 0.43$ & $-0.49 \pm 0.96$ & $1.87 \pm 0.65$ & $0.09 \pm 1$ & $-1.09 \pm 0.19$ & $-1.67 \pm 0.31$ & $-3.11 \pm 0.28$ \\
\hline mir-375 & $0.22 \pm 0.22$ & $-0.04 \pm 0.23$ & $-0.04 \pm 0.14$ & $0.33 \pm 0.32$ & $1.16 \pm 0.41$ & $0.92 \pm 0.23$ & $1.39 \pm 0.2$ \\
\hline mir-21 & $0.62 \pm 0.23$ & $-0.15 \pm 0.39$ & $0.11 \pm 0.36$ & $0.17 \pm 0.27$ & $1.07 \pm 0.74$ & $1.44 \pm 0.65$ & $2.13 \pm 0.14$ \\
\hline mir-146a & $0.19 \pm 0.18$ & $-0.61 \pm 0.48$ & $-0.62 \pm 0.32$ & $0.3 \pm 0.08$ & $1.63 \pm 0.99$ & $2.05 \pm 0.64$ & $2.7 \pm 0.23$ \\
\hline mir-31 & $-0.42 \pm 0.31$ & $-1.39 \pm 0.15$ & $-1.14 \pm 0.11$ & $-0.63 \pm 0.08$ & $1.1 \pm 0.71$ & $1.67 \pm 0.13$ & $1.82 \pm 0.26$ \\
\hline mir-150 & $-0.52 \pm 0.06$ & $-1.38 \pm 0.47$ & $-1.46 \pm 0.23$ & $-0.88 \pm 0.08$ & $-0.87 \pm 0.21$ & $-0.92 \pm 0.33$ & $-0.29 \pm 0.1$ \\
\hline mir-197 & $-0.65 \pm 0.17$ & $-1.01 \pm 0.42$ & $-1.09 \pm 0.12$ & $-0.78 \pm 0.27$ & $-0.66 \pm 0.21$ & $-0.23 \pm 0.25$ & $-0.13 \pm 0.21$ \\
\hline mir-328 & $-0.61 \pm 0.11$ & $-1.43 \pm 0.18$ & $-0.88 \pm 0.06$ & $-1.11 \pm 0.14$ & $-0.96 \pm 0.15$ & $-0.44 \pm 0.12$ & $-0.22 \pm 0.39$ \\
\hline mir-203 & $0.06 \pm 0.17$ & $0.42 \pm 0.13$ & $0.11 \pm 0.2$ & $-0.01 \pm 0.13$ & $0.29 \pm 0.27$ & $0.01 \pm 0.28$ & $1 \pm 0.2$ \\
\hline mir-136 & $0.18 \pm 0.06$ & $0.13 \pm 0.14$ & $0.08 \pm 0.09$ & $0.32 \pm 0.11$ & $0.59 \pm 0.12$ & $0.59 \pm 0.19$ & $1.02 \pm 0.11$ \\
\hline mir-126-3p & $0.32 \pm 0.14$ & $0 \pm 0.17$ & $-0.36 \pm 0.59$ & $0.09 \pm 0.35$ & $0.2 \pm 0.33$ & $-0.46 \pm 0.24$ & $-0.8 \pm 0.16$ \\
\hline mir-148a & $0.4 \pm 0.32$ & $-0.22 \pm 0.55$ & $0.49 \pm 0.17$ & $0.11 \pm 0.52$ & $-0.29 \pm 0.23$ & $-0.82 \pm 0.2$ & $-0.58 \pm 0.18$ \\
\hline mir-152 & $0.26 \pm 0.29$ & $0.45 \pm 0.28$ & $0.07 \pm 0.19$ & $-0.06 \pm 0.52$ & $-0.14 \pm 0.14$ & $-0.84 \pm 0.2$ & $-1.05 \pm 0.2$ \\
\hline mir-29b & $0.89 \pm 0.19$ & $-0.22 \pm 0.34$ & $-0.15 \pm 0.21$ & $0.77 \pm 0.14$ & $0.6 \pm 0.45$ & $-0.01 \pm 0.11$ & $1 \pm 0.13$ \\
\hline mir-182 & $0.58 \pm 0.11$ & $0.45 \pm 0.09$ & $0.72 \pm 0.07$ & $0.46 \pm 0.06$ & $0.16 \pm 0.08$ & $0.44 \pm 0.11$ & $0.29 \pm 0.1$ \\
\hline mir-141 & $0.33 \pm 0.54$ & $0.22 \pm 0.52$ & $0.86 \pm 0.28$ & $0.74 \pm 0.47$ & $0.8 \pm 0.52$ & $0.03 \pm 0.29$ & $0.6 \pm 0.35$ \\
\hline mir-451 & $-1.3 \pm 0.2$ & $-1.79 \pm 0.3$ & $-1.73 \pm 0.78$ & $-0.58 \pm 0.73$ & $-2.21 \pm 0.44$ & $-1.95 \pm 0.08$ & $-2.04 \pm 0.24$ \\
\hline mir-638 & $-1.45 \pm 0.25$ & $-0.77 \pm 0.5$ & $-1.29 \pm 0.54$ & $-1.19 \pm 0.5$ & $-1.07 \pm 0.23$ & $-0.83 \pm 0.36$ & $-1.47 \pm 0.11$ \\
\hline
\end{tabular}

The different probes spotted on chips showed no significant fold variation. wtC-PTC, classical papillary thyroid carcinoma $B R A F$ wild type; mutC-PTC, classical papillary thyroid carcinoma BRAF V600E; FV-PTC, follicular variant of papillary thyroid carcinoma; FTC, follicular thyroid carcinoma; FTA, follicular thyroid adenoma; WDT-UMP, well-differentiated tumour of uncertain malignant potential; FT-UMP, follicular tumour of uncertain malignant potential.

\section{Expression of miRNA in thyrocytes is altered}

ISH was performed on frozen tissue sections. An additional section was stained with $\mathrm{HE}$ for overall morphology (not shown). Figure 4A and B show that $m i R-7, m i R-200 b, m i R-221$, and $m i R-222$ expression was restricted to thyrocytes. Normal thyroid tissues showed diffuse weak expression of these miRNAs (not shown). ISH with miR-221 and miR-222 showed moderate-to-strong expression in the C-PTC compared with other tumors. In particular, expression was strongly increased in C-PTC in comparison with WDT-UMP specimens. Low expression of $m i R-7$ and $m i R-200 b$ was observed in FTC (Fig. 4B, a, b), compared with that observed in 


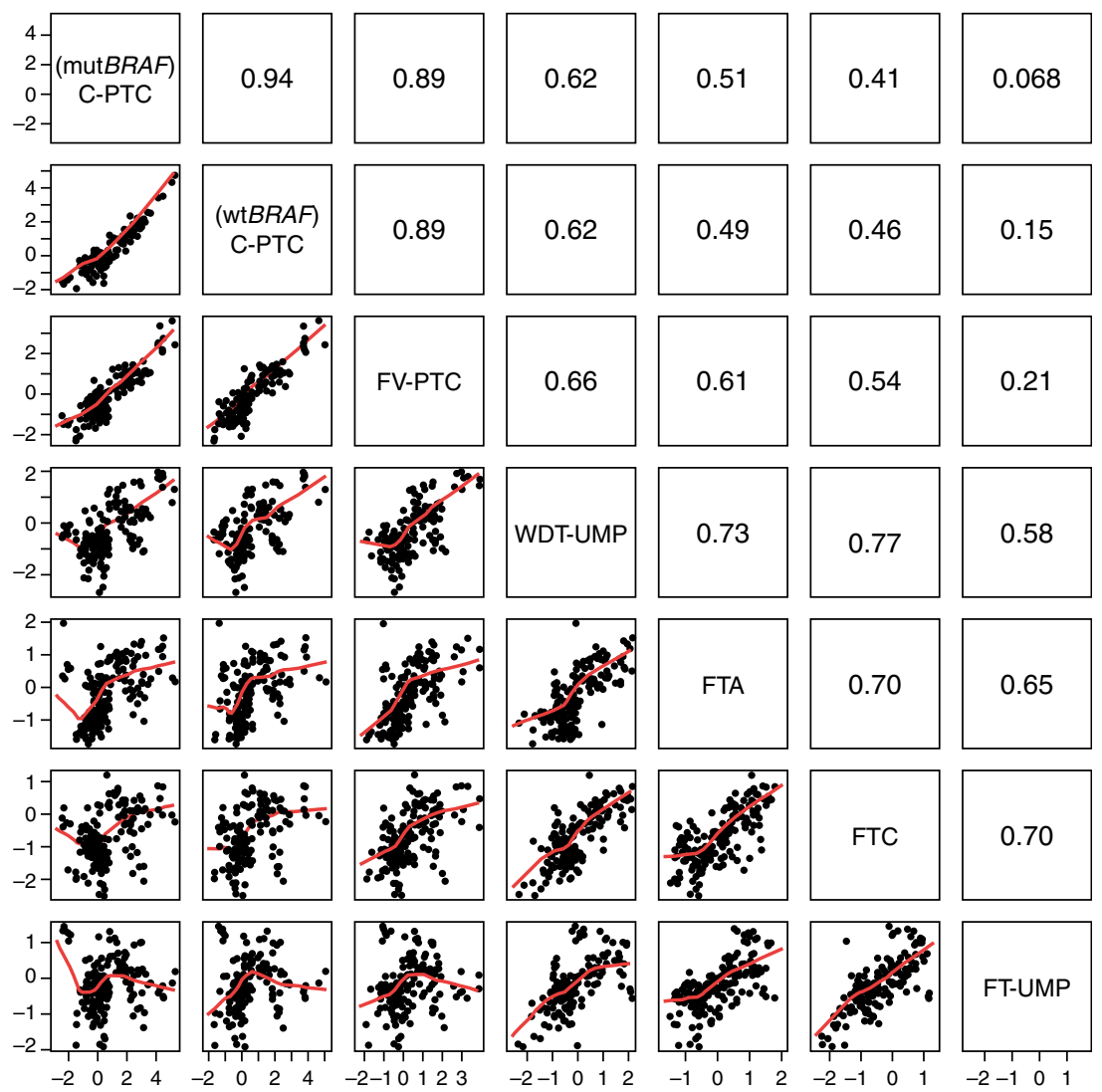

Figure 2 Correlation between average $\log _{2}$ (ratios) for C-PTC (wild-type BRAF), C-PTC (mutated BRAF), FV-PTC, adenoma, FTC,

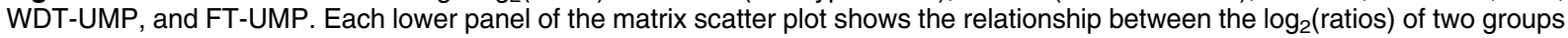
with names given on the diagonal. Each point corresponds to one miRNA probe found differentially expressed by linear model analysis (Smyth 2005). The interpolation plot is shown in red. Each symmetric upper panel indicates the corresponding Pearson's coefficient of correlation between the two groups.

FT-UMP (Fig. 4B, d, e), in agreement with the microarray data. The specificity of the reaction was shown by RNAase digestion before ISH (not shown) and by using a scrambled LNA probe instead of specific miRNAs (Fig. 4A, c, f and B, c, f).

\section{Supervised classification of thyroid samples}

To evaluate more precisely the relationships between WDT-UMP and FT-UMP on the one hand, and FTA, C-PTC, FV-PTC, and FTC on the other hand, we used the supervised classification method described by Culhane et al. (2005). A between-group analysis (BGA) of microarray data was performed to ordinate the groups rather than the individual samples. It has been shown that the BGA of microarray data was performed by comparing other supervised classification methods, including support vector machines and neural networks (Culhane et al. 2005). Each three-dimensional plot in Fig. 5 illustrates the distribution of the training set of clinical samples in a three-dimensional space that integrates all the variations within the FTA, C-PTC, FTC, and FV-PTC samples. The coordinates of the supplementary samples (FT-UMP and WDT-UMP) were represented in the same three-dimensional space. A color code was used to position the data points according to the third axis of projection (CS3), and a vertical bar indicates the distance to the second axis of the projection $(\mathrm{CS} 2=0)$. Each three-dimensional plot corresponds to one clinical condition (C-PTC, FV-PTC, WDT-UMP, FTA, FT-UMP, or FTC), and each point within each three-dimensional plot represents one patient from that group. These plots well illustrate the compactness of the FTA and C-PTC groups, as well as the more widespread distribution of the WDT-UMP, FT-UMP, FTC, and FV-PTC samples. This representation points to the fact that miRNA can be used to distinguish between C-PTC and FTA but are probably not sufficient per se to characterize the other groups. 


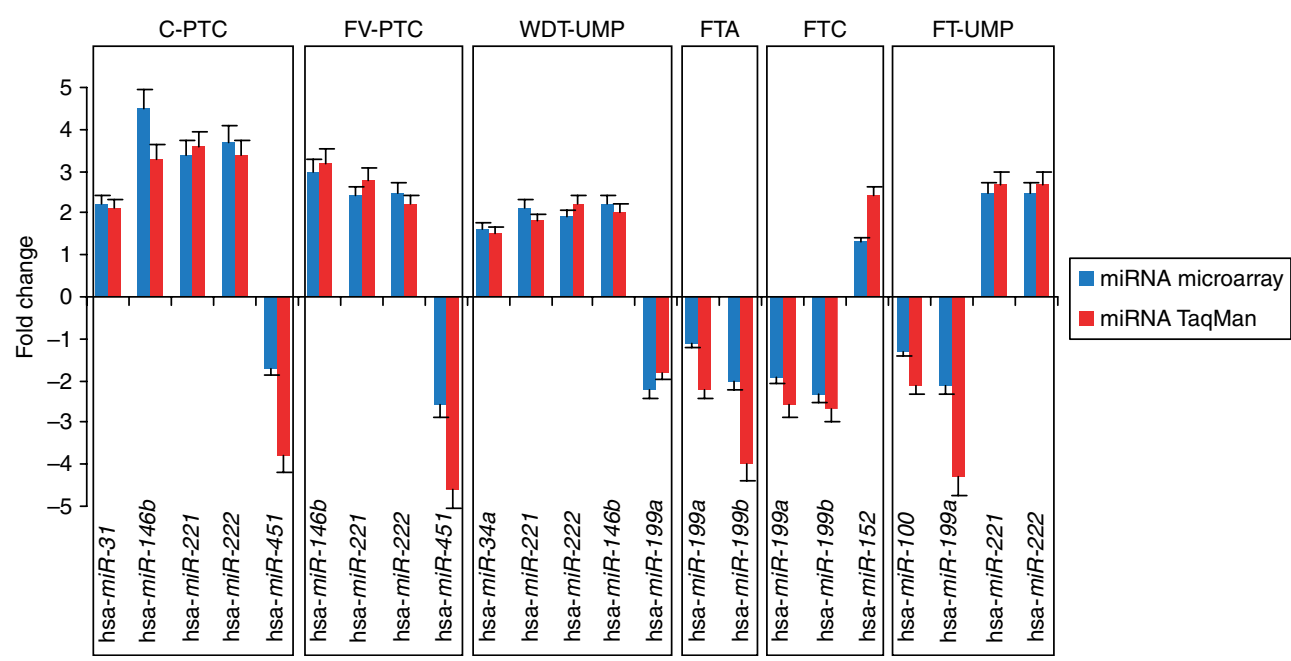

Figure 3 Quantitative RT-PCR analysis of a set of selected miRNA strongly regulated in different families of thyroid tumors. Comparison of qRT-PCR results (red) and microarray data (blue) showed similar expression levels for miR-31, miR-146b, miR-221, miR-222, and miR-451 on C-PTC; miR-146b, miR-221, miR-222, and miR-451 on FV-PTC; miR-199a, miR-34a, miR-146b, miR-221, and miR-222 on WDT-UMP; miR-199a and miR-199a on FTA; miR-199a, miR-199b, and miR-152 on FTC; and miR-100miR-199a, miR-221, and miR-222 on FT-UMP.

\section{miRNA expression profiles differ among categories of WDT tumors}

Table 4 and Fig. 1 summarize the results obtained for miRNAs that displayed the largest range of variation. We observed that several groups of miRNAs were useful to define the sample class. For instance, group 1, composed of $m i R-513$ and $m i R-494$, appeared to be more strongly decreased in FTA than in other samples. Group 2, composed of miR-26a, miR-27a, miR-125a, $m i R-130 a$, and $m i R-143$, appeared to be more strongly inhibited in FTC than in other samples. Group 4, composed of $m i R-7$ and $m i R-345$, appeared to be increased in TT-UMP and decreased in PTCs. Group 6, composed of $m i R-31, m i R-375, m i R-21$ and $m i R-146 a$, appeared to be increased in PTCs. Group 7, composed of $m i R-15 a, m i R-181 b, m i R-222 a, m i R-221, m i R-34 a$, and $m i R-146 b$, appeared to be increased in PTCs, but also in FTA and in WDT-UMP. Group 8, composed of $m i R-203, m i R-136, m i R-126-3 p, m i R-148 a$, and $m i R-152$, was helpful in distinguishing mutBRAF and $\mathrm{wt} B R A F$ samples of C-PTC from other samples.

A direct comparison of the signature of FT-UMP and WDT-UMP was able to reveal differences in miRNA expression between the two conditions. For instance, differential expression of $m i R-221$, $m i R-146 b, m i R-222 a, m i R-451$, and $m i R-7$ was observed between the two groups.

To better define the miRNA profile of the different PTCs studied, we also compared samples according to histological or genetic features. C-PTC and FV-PTC demonstrated a very similar miRNA signature. Interestingly, miRNA expression of C-PTC with a $B R A F$ mutation versus C-PTC without a $B R A F$ mutation showed that $m i R-203$ was more highly expressed in $B R A F$-mutated C-PTC in comparison with non- $B R A F$-mutated cases.

\section{Discussion}

It is difficult to morphologically evaluate the risk of malignancy associated with some WDT of the thyroid gland, as well as the prognosis of WDT in general (Franc et al. 2003). In this regard, interest has been raised in defining additional categories of thyroid tumors, namely WDT-UMP and FT-UMP

Table 5 qPCR mean of fold changes of the validation cohort between non-tumoral and tumoral tissue

\begin{tabular}{lrcrcc}
\hline & \multicolumn{2}{c}{ FT-UMP } & & \multicolumn{2}{c}{ WDT-UMP } \\
\cline { 2 - 3 } \cline { 5 - 6 } MicroRNAs & qPCR & P values & & qPCR & P values \\
\hline mir-221 & 2.62 & $\leq 0.001$ & & 3.56 & $\leq 0.001$ \\
mir-222 & 1.83 & $\leq 0.001$ & & 3.01 & $\leq 0.001$ \\
mir-146b & 0.50 & $\mathrm{NS}$ & & 1.96 & $\leq 0.01$ \\
mir-200b & 0.73 & $\mathrm{NS}$ & & -0.34 & $\mathrm{NS}$ \\
mir-7 & 1.25 & $\leq 0.001$ & & -1.30 & $\leq 0.01$ \\
mir-181b & 0.31 & $\mathrm{NS}$ & & 0.78 & $\mathrm{NS}$ \\
mir-21 & -0.43 & $\mathrm{NS}$ & & -0.80 & $\mathrm{NS}$ \\
mir-31 & -1.88 & $\leq 0.05$ & & -1.35 & $\mathrm{NS}$ \\
mir-100 & -1.22 & $\leq 0.01$ & & -0.90 & $\mathrm{NS}$ \\
mir-199a & -1.92 & $\mathrm{NS}$ & & -3.50 & $\leq 0.001$ \\
\hline
\end{tabular}

NS, not significant. 

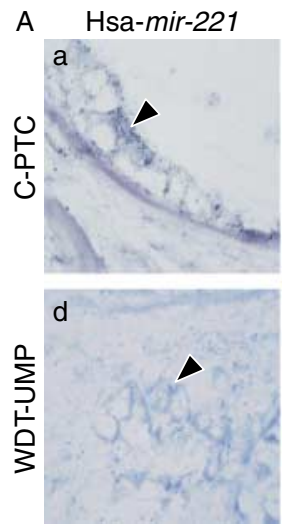
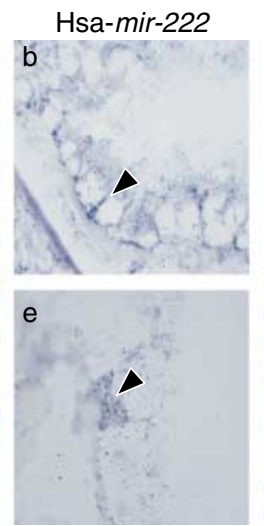
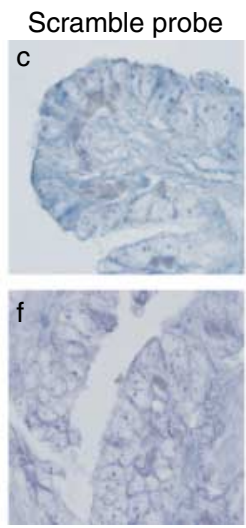
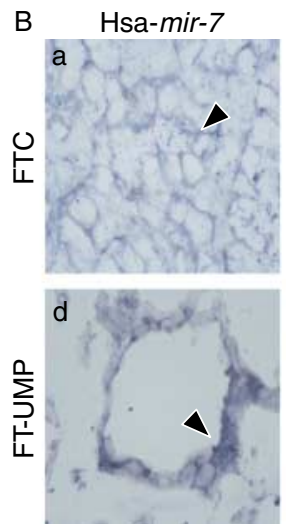

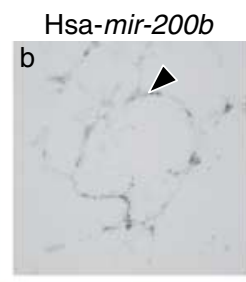

Scramble probe

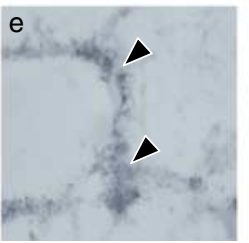

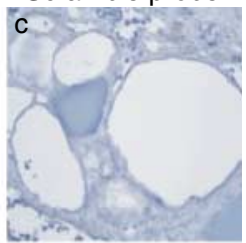

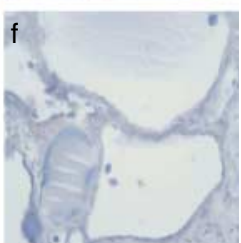

Figure 4 Comparison of the expression of selected miRNAs using in situ hybridization with locked nucleic acid probes for miR-7, miR-200b, miR-221, and miR-222 for different thyroid tumors. (A) Overexpression of miR-221, and miR-222 is observed in C-PTC $(a, b)$, compared to that observed in WDT-UMP (d, e). The scrambled control LNA probe showed no hybridization signal (c, f) (a-f, original magnification $\times 630$ ). (B) Low expression of miR-7 and miR-200b is observed in FTC (a, b), compared to that observed in FT-UMP $(d, e)$. The scrambled control LNA probe showed no hybridization signal $(c, f)(a-c$, $f$, original magnification $\times 400$; $\mathrm{d}$, e, original magnification $\times 630$ ). miRNA expression was mainly observed in thyrocytes (indicated by arrowheads).

(Williams 2000, Rosai 2005, Fonseca et al. 2006). These tumors represent borderline lesions that are difficult to diagnose morphologically, since they lie between FTA, FV-PTC, and minimally invasive FTC. However, information about WDT-UMP and FT-UMP is still limited and largely debated (Baloch \& LiVolsi 2007). Moreover, despite a number of recent studies, ancillary methods have had a low impact on aiding the diagnosis of such lesions (Rosai 2005, Fonseca et al. 2006, Fontaine et al. 2008).
In the last decade, there has been growing interest in the study of miRNA in various physiological and pathophysiological conditions (Bartel 2004, Baulcombe 2005, Croce \& Calin 2005, Mattick \& Makunin 2005, Pasquinelli et al. 2005, Waldman \& Terzic 2009). Different analyses have shown that altered expression of specific miRNA genes contributes to the initiation and progression of several types of cancer including thyroid carcinoma (Calin et al. 2004, Takamizawa et al. 2004, Chan et al. 2005,
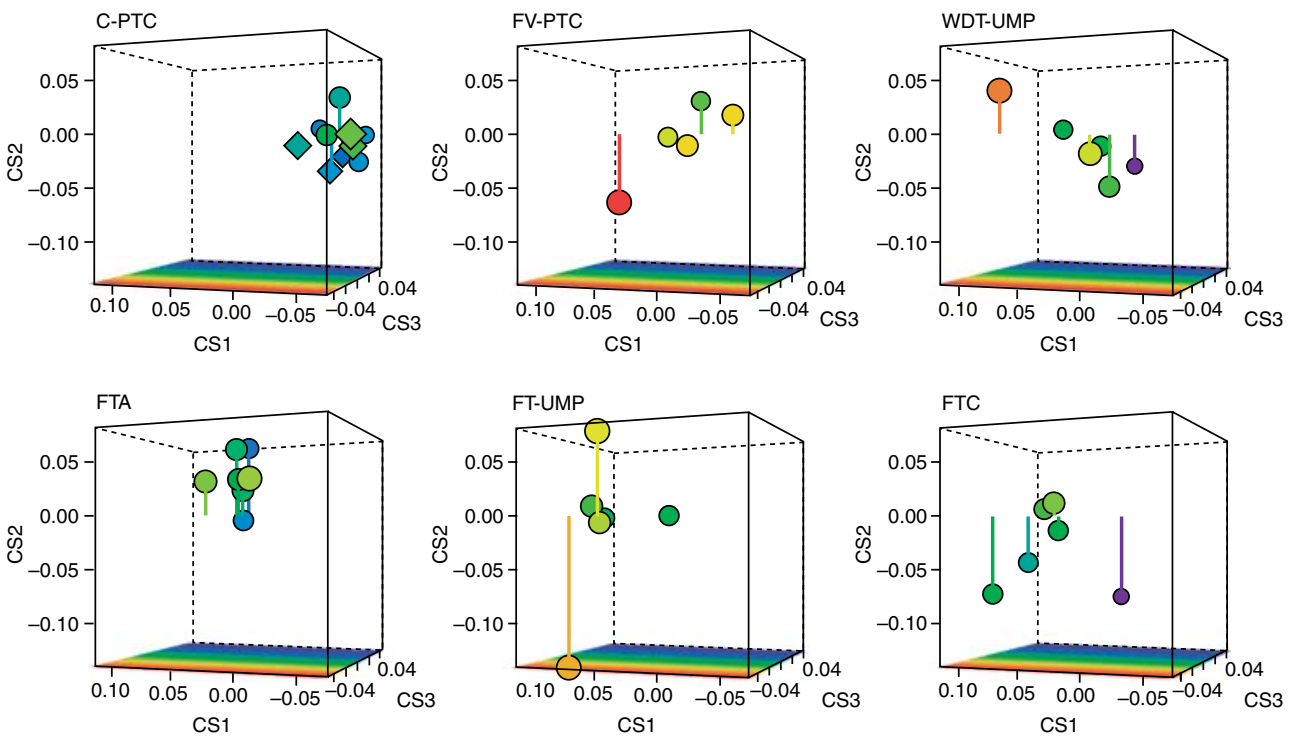

Figure 5 Three-dimensional scatter plot of the 42 patients. The data set of the 42 patients was analyzed using the BGA function (between-group analysis) available from the MADE4 package from Bioconductor (Culhane et al. 2005). A principal component analysis was performed on groups rather than on individual samples to define a three-dimensional space maximizing variations between the four reference groups (C-PTC, FV-PTC, FTA, and FTC). All 42 samples were then projected into this three-dimensional space. WDT-UMP and FT-UMP were treated as supplementary data and were projected into the same three-dimensional space. 
He et al. 2005a,b, Iorio et al. 2005, 2007, Lu et al. 2005, Ortholan et al. 2009). However, the determination and the use of a miRNA signature in TT-UMP have not been established previously.

The paucity of tools to evaluate the diagnosis and prognosis of some WDT of the thyroid gland was the initial justification for this study. We show that the different categories of WDT of the thyroid gland, including the so-called TT-UMPs, can be separated according to the level of expression of a small panel of miRNAs. Our data showed the existence of distinct profiles for WDT-UMPs, FT-UMPs, FTAs, PTCs (C-PTCs and FT-PTCs), and FTCs. The FT-UMPs were located in a region that is intermediate between FTAs and FTCs (Fig. 5), while WDT-UMPs samples were located in a region that is intermediate between FTAs, FV-PTCs, and C-PTCs samples. Supervised classification approaches were helpful in positioning these different groups of WDT. More specifically, we hypothesized that expression of some miRNAs might be altered in TT-UMP. However, rather than a specific alteration of expression for one or both groups of TT-UMP, we found that several miRNAs previously associated with PTC, FTC, or FTA were also deregulated in TT-UMPs, possibly at a lower or even sometimes at an opposite level. Moreover, as described previously (He et al. 2005a, Pallante et al. 2006, Tetzlaff et al. 2007, Nikiforova et al. 2008, 2009, Sheu et al. 2010), we confirmed in our cohort of 16 PTC that $m i R-221, m i R-222 a, m i R-146 a, m i R-146 b, m i R-21$, and $m i R-31$ were robustly overexpressed in this category of WDT (both in C-PTC and in FV-PTC). Interestingly, our results also showed increased expression of $m i R-221$ and $m i R-222 a$ in some TT-UMP samples. The expression of miR-146a and miR-146b was strongly increased in PTC (both in C-PTC and in FV-PTC). $m i R-146 b$ was slightly increased in WDTUMP and FTA. Thus, a small set of miRNAs (i.e. $m i R-146 a, m i R-146 b, m i R-221$, and $m i R-222 a$ ) can be useful to distinguish between WDT-UMP and PTCs (either FV-PTC or C-PTC) and FTA. In this regard, a previous study demonstrated that mir-146b was not overexpressed in a group of borderline lesions intermediate between FTA and FV-PTC (Chen et al. 2008). Sheu et al. (2010) have recently shown that only $m i R-146 b$ was significantly upregulated when comparing mean values of FV-PTC with WDT-UMP. Minimally invasive FTC can be difficult to distinguish morphologically from some FTA and might sometimes be diagnosed as FT-UMP (Williams 2000, De Lellis et al. 2004, Rosai 2005). Our study shows that expression of $m i R-7$ and $m i R-200 b$ was altered in FTC relative to FT-UMP. Finally, the miRNA signature of FV-PTC was quite similar to that of C-PTC, sharing many traits, such as the overexpression of $m i R-221, m i R-222, m i r-146 a$, and $m i R-146 b$.

To localize the cellular origin of some of the miRNAs identified in our study, we performed ISH on a panel of WDT of the thyroid gland. Data presented in Fig. 4 confirmed the higher expression of $m i R-221$ and $m i R-222 a$ in C-PTC than in WDT-UMP and the higher expression of $m i R-7$ and $m i R-200 b$ in FT-UMP than in FTC. Moreover, ISH allowed us to demonstrate that this overexpression was specific to epithelial cells.

A previous study has demonstrated that $m i R-221$ was also overexpressed in the non-tumor tissue of patients with C-PTC (He et al. 2005a). We could not confirm this data. Several elements can explain this discrepancy. First, it may be due to the fact that in our study, the different frozen specimens, used as paired non-tumor tissue, were taken from further away (i.e. at least $2 \mathrm{~cm}$ ) from the C-PTC, in the same lobe or in the contralateral lobe, than in the study by $\mathrm{He}$ et al. (2005a). Secondly, we always checked the morphology of the corresponding non-tumor specimens on frozen sections before RNA extraction. This procedure allowed us to eliminate potential papillary microcarcinoma of the thyroid around the main tumor. Thirdly, in our study, the global analysis of miRNAs in the corresponding non-tumor tissue, in comparison with the miRNA profile in a unique normal thyroid tissue, did not reveal significant differences.

If major advances in the characterization of mutations and chromosomal rearrangements in WDT of the thyroid gland have been made, the impact of these different modifications on the miRNA signature in these tumors has been poorly investigated to date. $B R A F$ mutations are detected in around half of the C-PTC (Xing 2005, Lassalle et al. 2010). In particular, the most frequent mutation, a V600E amino acid substitution, has been described in more than 800 C-PTC, with a prevalence of 20-69\% in the different studies (Puxeddu et al. 2004, Trovisco et al. 2004, 2005, Xing 2005, Lassalle et al. 2010). Intragenic $B R A F$ mutations seem to be almost completely restricted to non-radiation-induced cancers from the adult population (Lima et al. 2004). Several studies have reported that this mutation is related to poor prognosis in patients with C-PTC (Namba et al. 2003, Nikiforova et al. 2003, Giordano et al. 2005, Vasko et al. 2005, Xing et al. 2005, Adeniran et al. 2006, Lee et al. 2007). Conversely, the type and prevalence of $B R A F$ mutations differ in FV-PTC from those detected in C-PTC (Trovisco et al. 2004). Thus, FV-PTC cases are characterized by a low prevalence $(10 \%)$ of K601E (Trovisco et al. 2004). The most distinctive molecular 
features of follicular carcinoma are a high prevalence of $P A X 8-P P A R \gamma$ rearrangements and $R A S$ mutations. The $P A X 8-P P A R \gamma$ fusion gene has been detected in a high percentage of FTC (22-53\%; Kroll et al. 2000, Nikiforova et al. 2002). This fusion gene has also been detected in FV-PTC (25\%; Castro et al. 2006). RAS mutations are frequently detected in follicular adenomas and follicular carcinomas but do not provide any useful information from a diagnostic standpoint (Namba et al. 1990). Finally, distinct forms of RET mutations have been found in different WDTs of the thyroid gland. Rearrangements with other genes such as that of the RET/PTC oncogene have been demonstrated to play a causative role in a significant number of thyroid tumors (De Lellis et al. 2004). In our study, we were not able to find any miRNA signature significantly associated with the different mutations and rearrangements observed for WDT of the thyroid gland. This finding may imply that alterations in miRNA expression correspond to a late event in the pathogenesis of thyroid carcinogenesis. Further studies with additional cases, in particular for the $P A X 8-P P A R \gamma$ rearrangement, will now be needed to associate specific miRNA profiles with different molecular characterization of WDTs. In our C-PTC samples, the impact of the mutations on BRAF appeared to be more quantitative than qualitative: both were associated with a similar miRNA signature, but levels of variation were often magnified when $B R A F$ was mutated. Notably, $m i R-203$ was differentially expressed in C-PTC with a $B R A F$ mutation compared to all other conditions. This result has to be confirmed by $\mathrm{qPCR}$ on a larger group of $B R A F$ mutated and non-mutated C-PTC samples. Interestingly, Nikiforova et al. (2008) showed that $m i R-221$, $m i R-222$, and $m i R-146 b$ were strongly upregulated in tumors carrying a $B R A F$ mutation, whereas Chou et al. (2010) found that $m i R-146 b$ had a more significant upregulation in $B R A F$-mutated C-PTC.

The miRNAs regulated in thyroid tumors are present on the chip designed for this study. However, it could be of interest to check the results with other commercially available miRNA chips containing a more exhaustive list of currently known sequences of human miRNAs. This should not only confirm the results of this study but also allow the discovery of new miRNA involved in thyroid pathology.

A potential criticism of the results lies in the fact that the miRNA signatures were obtained from whole tumor specimens since molecular heterogeneity can be present in the same tumor. To increase the variation in miRNA expression observed between the different sub-cohorts of tumors, an interesting approach may be to select different areas and foci of interest in these tumors using laser capture microdissection (LCM) before miRNA extraction. Inclusion of LCM to harvest a more homogenous cell population may avoid the heterogenous expression repertoire of miRNA. This approach and the interest in performing geographical mapping of thyroid tumors have been demonstrated in a previous study (Aherne et al. 2008).

The inclusion of 35 TT-UMP cases, in this study, represents the largest panel of such samples ever studied by miRNA analysis. Our results demonstrate for the first time that FT-UMP and WDT-UMP samples differ slightly from PTCs (both C-PTCs and FV-PTCs), FTCs, and FTAs in their miRNA signatures. While we strongly believe that these results strengthen the existence of TT-UMPs as distinct clinical entities, this has to be confirmed on a larger panel of TT-UMP patients. Supervised classification suggests a distinct status for FT-UMP and WDT-UMP, the former being nearer to FTA than the latter.

\section{Declaration of interest}

The authors declare that there is no conflict of interest that could be perceived as prejudicing the impartiality of the research reported.

\section{Funding}

This work was supported by the Institut National du Cancer (INCa) (V Hofman, P Barbry, P Brest, B Mari, C Loubatier, and P Hofman; PL0079, 07/3D1616/Pdoc-110-32/NG-NC, R06080AA), the Association pour la recherche contre le Cancer (M-P Puisségur), the European Community (P Brest and B Mari; MICROENVIMET, FP7-HEALTH-F2-2008201279), and the CHUN-CNRS (S Lassalle).

\section{Acknowledgements}

We acknowledge the excellent support of the LPCE Platform of the Marseille-Nice Canceropole PACA for the molecular biology experiments and of the Nice-Sophia Antipolis Functional Genomics Platform of the Marseille-Nice Genopole for the microarray experiments.

\section{References}

Adeniran AJ, Zhu Z, Gandhi M, Steward DL, Fidler JP, Giordano TJ, Biddinger PW \& Nikiforov YE 2006 Correlation between genetic alterations and microscopic features, clinical manifestations, and prognostic characteristics of thyroid papillary carcinomas. American Journal of Surgical Pathology 30 216-222. (doi:10.1097/ 01.pas.0000176432.73455.1b) 
Aherne ST, Smyth PC, Flavin RJ, Russell SM, Denning KM, Li JH, Guenther SM, O'Leary JJ \& Sheils OM 2008 Geographical mapping of a multifocal thyroid tumour using genetic alteration analysis \& miRNA profiling. Molecular Cancer 7 89. (doi:10.1186/1476-4598-7-89)

Babak T, Zhang W, Morris Q, Blencowe BJ \& Hughes TR 2004 Probing microRNAs with microarrays. RNA 10 1813-1819. (doi:10.1261/rna.7119904)

Baloch ZW \& LiVolsi VA 2007 Our approach to follicularpatterned lesions of thyroid. Journal of Clinical Pathology 60 244-250. (doi:10.1136/jcp.2006.038604)

Bartel DP 2004 MicroRNAs: genomics, biogenesis, mechanism and function. Cell 116 281-297. (doi:10. 1016/S0092-8674(04)00045-5)

Baulcombe D 2005 RNA silencing. Trends in Biochemical Sciences 30 290-293. (doi:10.1016/j.tibs.2005.04.012)

Calin GA \& Croce CM 2006 a MicroRNA-cancer connection: the beginning of a new tale. Cancer Research $\mathbf{6 6}$ 7390-7394. (doi:10.1158/0008-5472.CAN-06-0800)

Calin GA \& Croce CM $2006 b$ MicroRNA signatures in human cancers. Nature Reviews. Cancer 6 857-866. (doi:10.1038/nrc1997)

Calin GA, Liu CG, Sevignani C, Ferracin M, Felli N, Dumitru CD, Shimizu M, Cimmino A, Zupo S, Dono M et al. 2004 MicroRNA profiling reveals distinct signatures in B cell chronic lymphocytic leukemias. PNAS 101 11755-11760. (doi:10.1073/pnas.0404432101)

Castro P, Rebocho AP, Soares RJ, Magalhães J, Roque L, Trovisco V, Vieira de Castro I, Cardoso-de-Oliveira M, Fonseca E, Soares P et al. 2006 PAX8-PPARg rearrangement is frequently detected in the follicular variant of papillary thyroid carcinoma. Journal of Clinical Endocrinology and Metabolism 91 213-220. (doi:10. 1210/jc.2005-1336)

Chan JA, Krichevsky AM \& Kosik KS 2005 MicroRNA-21 is an antiapoptotic factor in human glioblastoma cells. Cancer Research 65 6029-6033. (doi:10.1158/00085472.CAN-05-0137)

Chen YT, Kitabayashi N, Zhou XK, Fahey TJ III \& Scognamiglio T 2008 MicroRNA analysis as a potential diagnostic tool for papillary thyroid carcinoma. Modern Pathology 21 1139-1146. (doi:10.1038/modpathol. 2008.105)

Chou CK, Chen RF, Chou FF, Chang HW, Chen YJ, Lee YF, Yang KD, Cheng JT, Huang CC \& Liu RT 2010 miR-146b is highly expressed in adult papillary thyroid carcinomas with high risk features including extrathyroidal invasion and the BRAF(V600E) mutation. Thyroid 20 489-494. (doi:10.1089/thy.2009.0027)

Croce CM \& Calin GA 2005 MiRNAs, cancer and stem cell division. Cell 122 6-7. (doi:10.1016/j.cell.2005.06.036)

Culhane AC, Thioulouse J, Perrière G \& Higgins DG 2005 MADE4: an $\mathrm{R}$ package for multivariate analysis of gene expression data. Bioinformatics 21 2789-2790. (doi:10. 1093/bioinformatics/bti394)

De Lellis RA, Lloyd RV, Heitz PU \& Eng C (eds) 2004

Tumours of the thyroid and parathyroid. In World Health
Organisation Classification of Tumours. Pathology and Genetics of Tumours and Endocrine Organs. pp 49-103. International Agency for Research on Cancer (IARC), Lyon, France: IARC Press.

Fonseca E, Soares P, Cardoso-Oliveira M \& SobrinhoSimões M 2006 Diagnostic criteria in well-differentiated thyroid carcinomas. Endocrine Pathology 17 109-117. (doi:10.1385/EP:17:2:109)

Fontaine JF, Mirebeau-Prunier D, Franc B, Triau S, Rodien P, Houlgatte R, Malthièry Y \& Savagner F 2008 Microarray analysis refines classification of non-medullary thyroid tumours of uncertain malignancy. Oncogene 27 2228-2236. (doi:10.1038/sj.onc.1210853)

Franc B, de la Salmonière P, Lange F, Hoang C, Louvel A, de Roquancourt A, Vildé F, Hejblum G, Chevret S \& Chastang C 2003 Interobserver and intraobserver reproducibility in the histopathology of follicular thyroid carcinoma. Human Pathology 34 1092-1100. (doi:10. 1016/S0046-8177(03)00403-9)

Giordano TJ, Kuick R, Thomas DG, Misek DE, Vinco M, Sanders D, Zhu Z, Ciampi R, Roh M, Shedden K et al. 2005 Molecular classification of papillary thyroid carcinoma: distinct BRAF, RAS, and RET/PTC mutationspecific gene expression profiles discovered by DNA microarray analysis. Oncogene 24 6646-6656. (doi:10. 1038/sj.onc.1208822)

He H, Jazdzewski K, Li W, Liyanarachchi S, Nagy R, Volinia S, Calin GA, Liu CG, Franssila K, Suster S et al. $2005 a$ The role of microRNA genes in papillary thyroid carcinoma. PNAS 102 19075-19080. (doi:10.1073/pnas. 0509603102)

He L, Thomson JM, Hemann MT, Hernando-Monge E, $\mathrm{Mu}$ D, Goodson S, Powers S, Cordon-Cardo C, Lowe SW, Hannon GJ et al. 2005b A microRNA polycistron as a potential human oncogene. Nature 435 828-833. (doi:10.1038/nature03552)

Huber W, von Heydebreck A, Sueltmann H, Poustka A \& Vingron M 2002 Variance stabilization applied to microarray data calibration and to the quantification of differential expression. Bioinformatics 18 (Supplement 1) S96-S104. (doi:10.1093/bioinformatics/18.suppl_1.S96)

Iorio MV, Ferracin M, Liu CG, Veronese A, Spizzo R, Sabbioni S, Magri E, Pedriali M, Fabbri M, Campiglio M et al. 2005 MicroRNA gene expression deregulation in human breast cancer. Cancer Research 65 7065-7070. (doi:10.1158/0008-5472.CAN-05-1783)

Iorio MV, Visone R, Di Leva G, Donati V, Petrocca F, Casalini P, Taccioli C, Volinia S, Liu CG, Alder H et al. 2007 MicroRNA signatures in human ovarian cancer. Cancer Research 67 8699-8707. (doi:10.1158/00085472.CAN-07-1936)

Kroll TG, Sarraf P, Pecciarini L, Chen CJ, Mueller E, Spiegelman BM \& Fletcher J 2000 PAX8-PPARg1 fusion oncogene in human thyroid carcinoma. Science 289 1357-1360. (doi:10.1126/science.289.5483.1357)

Lassalle S, Hofman V, Ilie M, Butori C, Bozec A, Santini J, Vielh P \& Hofman P 2010 Clinical impact of the detection 
of BRAF mutations in thyroid pathology: potential usefulness as diagnostic, prognostic and theragnostic applications. Current Medicinal Chemistry 17 1839-1850. (doi:10.2174/092986710791111189)

Le Brigand K \& Barbry P 2007 MEDIANTE: a web-based microarray data manager. Bioinformatics 23 1304-1306. (doi:10.1093/bioinformatics/btm106)

Le Brigand K, Russell R, Moreilhon C, Rouillard JM, Jost B, Amiot F, Magnone V, Bole-Feysot C, Rostagno P, Virolle V et al. 2006 An open-access long oligonucleotide microarray resource for analysis of the human and mouse transcriptomes. Nucleic Acids Research 34 e87. (doi:10. 1093/nar/gk1485)

Lee JH, Lee ES \& Kim YS 2007 Clinicopathologic significance of BRAF V600E mutation in papillary carcinomas of the thyroid: a meta-analysis. Cancer 110 38-46. (doi:10.1002/cncr.22754)

Legendre M, Ritchie W, Lopez F \& Gautheret D 2006 Differential repression of alternative transcripts: a screen for miRNA targets. PLoS Computational Biology 2 e43. (doi:10.1371/journal.pcbi.0020043)

Lima J, Trovisco V, Soares P, Máximo V, Magalhães J, Salvatore G, Santoro M, Bogdanova T, Tronko M, Abrosimov A et al. 2004 BRAF mutations are not a major event in post-Chernobyl childhood thyroid carcinomas. Journal of Clinical Endocrinology and Metabolism 89 4267-4271. (doi:10.1210/jc.2003-032224)

Lu J, Getz G, Miska EA, Alvarez-Saavedra E, Lamb J, Peck D, Sweet-Cordero A, Ebert BL, Mak RH, Ferrando AA et al. 2005 MicroRNA expression profiles classify human cancers. Nature 435 834-838. (doi:10. 1038/nature03702)

Ludwig JA \& Weinstein JN 2005 Biomarkers in cancer staging, prognosis and treatment selection. Nature Reviews. Cancer 5 845-856. (doi:10.1038/nrc1739)

Mattick JS \& Makunin IV 2005 Small regulatory RNAs in mammals. Human Molecular Genetics 14 R121-R132. (doi:10.1093/hmg/ddi101)

Namba H, Rubin SA \& Fagin JA 1990 Point mutations of ras oncogenes are an early event in thyroid tumorigenesis. Molecular Endocrinology 4 1474-1479. (doi:10.1210/ mend-4-10-1474)

Namba H, Nakashima M, Hayashi T, Hayashida N, Maeda S, Rogounovitch TI, Ohtsuru A, Saenko VA, Kanematsu T \& Yamashita S 2003 Clinical implication of hot spot BRAF mutation, V599E, in papillary thyroid cancers. Journal of Clinical Endocrinology and Metabolism $\mathbf{8 8}$ 4393-4397. (doi:10.1210/jc.2003-030305)

Nikiforova MN, Biddinger PW, Caudill CM, Kroll TG \& Nikiforov YE 2002 PAX8-PPARgamma rearrangement in thyroid tumors: RT-PCR and immunohistochemical analyses. American Journal of Surgical Pathology 26 1016-1023. (doi:10.1097/00000478-200208000-00006)

Nikiforova MN, Kimura ET, Gandhi M, Biddinger PW, Knauf JA, Basolo F, Zhu Z, Giannini R, Salvatore G, Fusco A et al. 2003 BRAF mutations in thyroid tumors are restricted to papillary carcinomas and anaplastic or poorly differentiated carcinomas arising from papillary carcinomas. Journal of Clinical Endocrinology and Metabolism 88 5399-5404. (doi:10.1210/jc.2003030838)

Nikiforova MN, Tseng GC, Steward D, Diorio D \& Nikiforov YE 2008 MicroRNA expression profiling of thyroid tumors: biological significance and diagnostic utility. Journal of Clinical Endocrinology and Metabolism 93 1600-1608. (doi:10.1210/jc.2007-2696)

Nikiforova MN, Chiosea SI \& Nikiforov YE 2009 MicroRNA expression in thyroid tumors. Endocrine Pathology 20 85-91. (doi:10.1007/s12022-009-9069-z)

Ortholan C, Puissegur MP, Ilie M, Barbry P, Mari B \& Hofman P 2009 MicroRNAs and lung cancer: new oncogenes and tumor suppressors, new prognostic factors and potential therapeutic targets. Current Medicinal Chemistry 16 1047-1061. (doi:10.2174/092986709787 581833)

Pallante P, Visone R, Ferracin M, Ferraro A, Berlingieri MT, Troncone G, Chiappetta G, Liu CG, Santoro M, Negrini M et al. 2006 MicroRNA deregulation in human thyroid papillary carcinomas. Endocrine-Related Cancer 13 497-508. (doi:10.1677/erc.1.01209)

Pallante P, Visone R, Croce CM \& Fusco A 2010 Deregulation of microRNA expression in follicular cell-derived human thyroid carcinomas. EndocrineRelated Cancer 17 F91-F104. (doi:10.1677/ERC-090217)

Papotti M, Rodriguez J, De Pompa R, Bartolazzi A \& Rosaï J 2005 Galectin-3 and HBME-1 expression in welldifferentiated thyroid tumors with follicular architecture of uncertain malignant potential. Modern Pathology 18 541-546. (doi:10.1038/modpathol.3800321)

Pasquinelli AE, Hunter S \& Bracht J 2005 MicroRNAs: a developing story. Current Opinion in Genetics \& Development 15 200-205. (doi:10.1016/j.gde.2005. 01.002)

Puxeddu E, Moretti S, Elisei R, Romei C, Pascucci R, Martinelli M, Marino C, Avenia N, Rossi ED, Fadda G et al. 2004 BRAF (V599E) mutation is the leading genetic event in adult sporadic papillary thyroid carcinomas. Journal of Clinical Endocrinology and Metabolism 89 2414-2420. (doi:10.1210/jc.2003-031425)

Rosai J 2005 Handling of thyroid follicular patterned lesions. Endocrine Pathology 16 279-283. (doi:10.1385/ EP:16:4:279)

Sheu S-Y, Grabellus F, Schwertheim S, Worm K, BroeckerPreuss M \& Schmid KW 2010 Differential miRNA expression profiles in variants of papillary thyroid carcinoma and encapsulated follicular thyroid tumours. British Journal of Cancer 102 376-382. (doi:10.1038/sj. bjc.6605493)

Smyth GK 2005 Limma: linear models for microarray data. In Bioinformatics and Computational Biology Solutions Using $R$ and Bioconductor, pp 397-420. Eds R Gentleman, V Carey, S Dudoit, R Irizarry \& W Huber. New York: Springer. 
Sobrinho-Simões M, Preto A, Rocha AS, Castro P, Máximo V, Fonseca E \& Soares P 2005 Molecular pathology of well-differentiated thyroid carcinomas. Virchows Archiv 447 787-793. (doi:10.1007/s00428005-0065-5)

Suster S 2006 Thyroid tumors with a follicular growth pattern: problems in differential diagnosis. Archives of Pathology \& Laboratory Medicine 130 984-988.

Takamizawa J, Konishi H, Yanagisawa K, Tomida S, Osada H, Endoh H, Harano T, Yatabe Y, Nagino M, Nimura Y et al. 2004 Reduced expression of the let-7 microRNAs in human lung cancers in association with shortened postoperative survival. Cancer Research 64 3753-3756. (doi:10.1158/0008-5472.CAN-04-0637)

Tetzlaff MT, Liu A, Xu X, Master SR, Baldwin DA, Tobias JW, Livolsi VA \& Baloch ZW 2007 Differential expression of miRNAs in papillary thyroid carcinoma compared to multinodular goiter using formalin fixed paraffin embedded tissues. Endocrine Pathology 18 163-173. (doi:10.1007/s12022-007-0023-7)

Triboulet R, Mari B, Lin YL, Chable-Bessia C, Bennasser Y, Lebrigand K, Cardinaud B, Maurin T, Barbry P, Baillat V et al. 2007 Suppression of microRNA-silencing pathway by HIV-1 during virus replication. Science $\mathbf{3 1 5}$ 1579-1582. (doi:10.1126/science.1136319)

Trovisco V, Vieira de Castro I, Soares P, Máximo V, Silva P, Magalhães J, Abrosimov A, Guiu XM \& SobrinhoSimões M 2004 BRAF mutations are associated with some histological types of papillary thyroid carcinoma. Journal of Pathology 202 247-251. (doi:10.1002/path. 1511)

Trovisco V, Soares P, Preto A, de Castro IV, Lima J, Castro P, Máximo V, Botelho T, Moreira S, Meireles AM et al. 2005 Type and prevalence of BRAF mutations are closely associated with papillary thyroid carcinoma histotype and patients' age but not with tumour aggressiveness. Virchows Archiv 446 589-595. (doi:10.1007/s00428-005-1236-0)
Vasko V, Hu S, Wu G, Xing JC, Larin A, Savchenko V, Trink B \& Xing M 2005 High prevalence and possible de novo formation of BRAF mutation in metastasized papillary thyroid cancer in lymph nodes. Journal of Clinical Endocrinology and Metabolism 90 5265-5269. (doi:10. 1210/jc.2004-2353)

Visone R, Pallante P, Vecchione A, Cirombella R, Ferracin M, Ferraro A, Volinia S, Coluzzi S, Leone V, Borbone E et al. 2007 Specific microRNAs are downregulated in human thyroid anaplastic carcinomas. Oncogene 26 7590-7595. (doi:10.1038/sj.onc.1210564)

Waldman SA \& Terzic A 2009 A study of microRNAs in silico and in vivo: diagnostic and therapeutic applications in cancer. FEBS Journal 276 2157-2164. (doi:10.1111/j.1742-4658.2009.06934.x)

Weber F, Teresi RE, Broelsch CE, Frilling A \& Eng C 2006 A limited set of human microRNA is deregulated in follicular thyroid carcinoma. Journal of Clinical Endocrinology and Metabolism 91 3584-3591. (doi:10. 1210/jc.2006-0693)

Williams ED 2000 Guest editorial: two proposals regarding the terminology of thyroid tumors. International Journal of Surgical Pathology 8 181-183. (doi:10.1177/ 106689690000800304)

Xing M 2005 BRAF mutation in thyroid cancer. EndocrineRelated Cancer 12 245-262. (doi:10.1677/erc.1.0978)

Xing M, Westra WH, Tufano RP, Cohen Y, Rosenbaum E, Rhoden KJ, Carson KA, Vasko V, Larin A, Tallini G et al. 2005 BRAF mutation predicts a poorer clinical prognosis for papillary thyroid cancer. Journal of Clinical Endocrinology and Metabolism 90 6373-6379. (doi:10.1210/jc.2005-0987)

Received in final form 16 June 2011

Accepted 18 June 2011

Made available online as an Accepted Preprint 21 June 2011 